\title{
COMPORTAMENTO ESTRATÉGICO: ESTUDO DE CASO EM UMA ORGANIZAÇÃO DO SETOR SUCROENERGÉTICO BRASILEIRO
}

\section{RESUMO}

O objetivo do presente trabalho consistiu em compreender o comportamento estratégico de uma organização do setor sucroenergético brasileiro. Especificamente, buscou-se descrever como ocorreu o processo de entrada da organização no setor sucroenergético brasileiro e categorizar o comportamento e o posicionamento estratégico da organização a partir da aplicação da tipologia de Miles e Snow (1978). A partir de uma pesquisa qualitativa, empregou-se o método de estudo de caso. Os dados foram coletados por meio de pesquisa documental e de entrevistas semiestruturadas junto a três diretores da empresa. Também foi utilizado, de forma complementar, um questionário fechado, elaborado por Conant et al. (1990) e adaptado por Gardelin (2010), com o objetivo de categorizar as estratégias utilizadas pela organização. Os resultados indicaram que a organização estudada possui um padrão de comportamento híbrido, variando entre prospector e analítico, caracterizando o posicionamento da empresa a partir de uma dupla estratégia: ora prospectando o ambiente e o setor competitivo, introduzindo uma perspectiva inovadora em sua atuação interna e externa; ora analisando estes contextos internos e externos na busca de uma inserção no mercado local e internacional mais efetiva. Logo, a tipologia de Miles e Snow apresenta-se como importante instrumento de pesquisa para a análise e adoção de determinados posicionamentos estratégicos e para a tomada de decisão, mostrando-se assim como quadro de referência para a realização de estudos que procurem compreender a realidade estratégica organizacional.

Palavras-chave: Estratégia; Administração Estratégica; Posicionamento; Miles e Snow; Etanol.

\section{STRATEGIC BEHAVIOR: CASE STUDY OF AN ORGANIZATION FROM THE BRAZILIAN ETHANOL INDUSTRY}

\begin{abstract}
The purpose of this paper is to understand the strategic behavior of an organization from the Brazilian ethanol industry. Specifically, this paper aimed to describe how the organization's entrance in the Brazilian ethanol industry occurred, and to identify the organization's positioning and strategic behavior through the application of Miles and Snow (1978) typology. Using a qualitative research design, a case study was conducted, based on documental research and semistructured interviews with three directors from the studied organization. We also utilized a structured questionnaire elaborated by Conant et al. (1990) and adapted by Gardelin (2010), aiming to categorize the strategies adopted by the organization. The results showed that the organization has a hybrid behavior pattern, varying from investigative to analytical, characterizing its strategic behavior through a dual strategy: on one hand, the organization investigates the environment and its competitive industry, introducing an innovative perspective in its external and internal operations; and on the other hand, the organization analyzes these internal and external contexts seeking a more effective positioning in national and international markets. Thus, Miles and Snow typology presents itself as an important research tool for the analysis and adoption of certain strategic positioning and decision making, establishing itself as a frame of reference for studies that seek to understand the strategic organizational reality.
\end{abstract}

Keywords: Strategy; Strategic Management; Positioning; Miles and Snow; Ethanol. 


\section{COMPORTAMIENTO ESTRATÉGICO: UN ESTUDIO DE CASO EN UNA CAÑA DE AZÚCAR BRASILEÑA ORGANIZACIÓN DEL SECTOR}

\section{RESUMEN}

El objetivo de este estudio fue comprender el desempeño estratégico de una organización de la industria de la caña de azúcar brasileña. Específicamente, se intentó describir como ocurrió con el proceso de inscripción de la organización en la industria de la caña de azúcar brasileña y categorizar el comportamiento y el posicionamiento estratégico de la organización de la aplicación de la tipología de Miles y Snow (1978). De un estudio cualitativo, se utilizó el método de estudio de caso. Los datos fueron recolectados a través de investigación y entrevistas semi-estructuradas escritorio con tres directores de la compañía. También se utiliza de forma complementaria, un cuestionario cerrado desarrollado por Conant et al. (1990) y adaptado por Gardelin (2010), con el objetivo de categorizar las estrategias utilizadas por la organización. Los resultados indicaron que la organización estudiada tiene un comportamiento híbrido estándar, que van desde prospector y analítico, con el posicionamiento de la empresa a partir de una doble estrategia: ahora prospección del medio ambiente y la industria competitiva mediante la introducción de una nueva perspectiva de sus operaciones internas y externa; ahora analizar estos contextos internos y externos en busca de una integración más efectiva en el mercado local e internacional. Por lo tanto, la tipología de Miles y Snow se presenta como una importante herramienta de investigación para el análisis y la adopción de ciertas posicionamiento y la toma de decisiones estratégicas, apareciendo así como un marco para la realización de estudios que tratan de comprender la realidad organización estratégica.

Palabras clave: Estrategia; Gestión Estratégica; Posicionamiento; Miles y Snow; El Etanol.

\footnotetext{
${ }^{1}$ Doutorando em Administração pela Universidade Federal de Lavras - UFLA. Professor da Universidade Federal de Uberlândia - UFU. Brasil. E-mail: alexfborges@gmail.com

2 Graduado em Administração pela Universidade Federal de Uberlândia - UFU. Brasil. E-mail: sidneyalvim@hotmail.com

${ }^{3}$ Doutorando em Administração pela Universidade Federal de Lavras - UFLA. Professor da Universidade Federal de Lavras - UFLA. Brasil. E-mail: $\underline{\text { mdleite@gmail.com }}$

${ }^{4}$ Doutor em Sociologia e Política pela Universidade Federal de Minas Gerais - UFMG. Professor da Universidade Federal de Uberlândia - UFU. Brasil. E-mail: alessandroenoque@pontal.ufu.br
} 


\section{INTRODUÇÃO}

Os biocombustíveis encontram-se, atualmente, em destaque no cenário econômico mundial. Por estarem em um estágio de desenvolvimento tecnológico mais avançado, em comparação com outras fontes de energia renovável e ecológica desenvolvidas, os biocombustíveis apresentam-se como uma alternativa relevante em iniciativas de substituição de produtos derivados do petróleo (Beltreschi, Neves, \& Antolini, 2012). Por sua vez, o etanol brasileiro de cana-de-açúcar tem sido considerado como uma das mais avançadas opções existentes para a produção de biocombustíveis em larga escala (Unica, 2012).

Nesse contexto, diversos grupos e organizações multinacionais vêm investindo no setor sucroenergético brasileiro, por meio de processos de internacionalização, de fusão e aquisição, da formação de joint ventures, ou, ainda, da criação de estruturas organizacionais e de modelos de negócios inovadores voltados para a exploração desse mercado (Feltre \& Paulillo, 2013; Soares et al., 2011). Tal fato tem gerado oportunidades de desenvolvimento econômico, bem como um campo fértil para a realização de estudos e pesquisas científicas, sobretudo na área de Estratégia Organizacional (Barbosa \& Cândido, 2013; Augusto, Takahashi, \& Sachuk, 2012).

Diante desse cenário, questiona-se: como se configura o comportamento estratégico de uma organização inserida no setor sucroenergético brasileiro? Para responder a este problema de pesquisa, o objetivo deste trabalho consistiu em compreender o comportamento estratégico de uma organização do setor sucroenergético brasileiro. Para tanto, o caso selecionado foi analisado a partir da aplicação da tipologia de Miles e Snow (1978). Esta tipologia apresenta quatro tipos de comportamento estratégico distintos: a) defensivo: organizações que não buscam oportunidades fora de seus domínios; b) prospectivo: organizações que constantemente buscam novas oportunidades criando mudanças e incertezas; c) analítico: organizações que combinam os pontos fortes das tipologias anteriores, operando ora em ambiente estável, ora em ambiente de mudança; e d) reativo: organizações que apresentam um padrão de adaptação ao seu ambiente. Especificamente, buscou-se descrever como ocorreu o processo de entrada da organização no Brasil e categorizar o comportamento estratégico da organização a partir da aplicação da tipologia de Miles e Snow (1978).

Este trabalho encontra-se dividido nas seguintes seções, além desta introdução: referencial teórico, compreendendo os tópicos a), estratégia em organizações e b) tipologia estratégica de Miles e Snow; procedimentos metodológicos; contexto da pesquisa: o setor sucroenergético brasileiro; resultados e discussão; conclusões; e referências.

\section{ESTRATÉGIA EM ORGANIZAÇÕES}

A verificação de elementos vinculados ao processo de formação de estratégias nas organizações tem sido um tema recorrente na literatura (Bulgacov et al., 2007; Borges, Freitas Jr., \& Oliveira, 2008). Os estudos sobre estratégia, em uma perspectiva histórica, assumem papel de destaque no campo da Administração, tanto ao nível nacional (Bertero, Vasconcelos, \& Binder, 2003; Colla, Martins, \& Kato, 2012), como ao nível internacional (Furrer, Thomas, \& Goussevskaia, 2008). A evolução da pesquisa em estratégia demonstra preocupações com aspectos conceituais, com a elaboração e aplicação de modelos de análise, e com a criação de ferramental de intervenção em diferentes realidades organizacionais.

O esforço de elaboração teórica no campo da estratégia em organizações recai, primeiramente, sobre o aspecto de definição daquilo que é, efetivamente, 'estratégia' (Nag, Hambrick, \& Chen, 2007; Whittington, 2006). A partir de sua aplicação nas pesquisas em Administração e Estudos Organizacionais, o termo estratégia assume diferentes conotações e evolui de forma sistemática, na medida em que o volume de produção científica permitiu a configuração de um campo de estudos particular, dinâmico e em consolidação (Ronda-Pupo \& GuerrasMartin, 2012). Nesse sentido, ao trazer a definição para o âmbito organizacional, Mintzberg et al. (2006) afirmam que estratégia é o padrão de decisões que: determina e revela os objetivos, propósitos ou metas de uma organização; produz as principais políticas e planos para a obtenção dessas metas; define a escala de negócios em que a organização deve se envolver; o tipo de organização econômica e humana que pretende ser; e a natureza da contribuição econômica e não econômica que pretende proporcionar a seus acionistas, funcionários e comunidades.

Mintzberg et al. (2000) apresentam cinco definições diferentes para o conceito de estratégia: plano, padrão, posição, perspectiva e truque. Cada definição abrange um aspecto particular do processo de formação de estratégia, e a visão do todo engloba a ação estratégica das organizações de maneira mais integrada que os conceitos tradicionais sobre o tema. De um lado, a estratégia como plano constitui a definição dos estrategistas em relação ao que se pretende alcançar em longo prazo. De outro, a estratégia como padrão refere-se a uma coerência de comportamento ao longo do tempo. Nesse momento, os autores diferenciam as estratégias deliberadas das estratégias emergentes. As estratégias deliberadas são as intenções plenamente realizadas, ou seja, aquilo que é pretendido pela alta administração sendo posteriormente realizado. Já no caso das estratégias emergentes, o padrão realizado não é, necessariamente, aquele que fora anteriormente pretendido. 
Adicionalmente, a estratégia como posição refere-se à localização de determinadas empresas e/ou produtos no mercado, em relação aos concorrentes, e a estratégia como perspectiva é proveniente da concepção pessoal dos estrategistas e de sua visão mais ampla sobre o futuro, definindo a 'maneira de atuar' das organizações. Por fim, a estratégia como um truque representa uma 'manobra' para enganar um concorrente. Dessa forma, toma-se como intenção real a ameaça, induzindo os concorrentes a uma percepção errônea de sua estratégia (Mintzberg et al., 2000).

Além dos esforços para o estabelecimento de unidade conceitual no campo, surgem iniciativas para se abarcar os diferentes enfoques e abordagens da estratégia enquanto um quadro teórico de amplitude e densidade reconhecida. Whittington (2006), por exemplo, abre possibilidades para a compreensão do campo de pesquisas em estratégia a partir de quatro perspectivas básicas do pensamento estratégico: clássica, evolucionária, sistêmica e processual. O autor afirma que, no contexto da escola clássica, o planejamento pode se adaptar e se antecipar as mudanças de mercado, a partir de estratégias desenvolvidas por meio de análise racional, afastada do "campo de batalha" dos negócios. Não obstante, surgem alternativas a esta visão clássica da estratégia. No âmbito da escola evolucionária, os mercados são imprevisíveis e difíceis para justificar grandes investimentos em planejamento estratégico, fato que sugere a manutenção de custos baixos e abertura a oportunidades de mercado. A escola processualista também questiona a abordagem clássica, pois defende que as estratégias eficazes emergem diretamente do envolvimento com as operações diárias e as forças básicas da organização. Por fim, a abordagem sistêmica argumenta que as estratégias devem ser "sociologicamente eficientes", apropriadas a contextos sociais específicos. Do ponto de vista sistêmico, não há um caminho melhor para se desenvolver uma estratégia, contrariando perspectivas prescritivas que dominam a área (Whittington, 2006).

A partir da pluralidade de conceitos, quadros teóricos e possibilidades de aplicação prática, revela-se a configuração de um campo de estudos multifacetado, o qual fornece diferentes vertentes de interpretação e ação. Por isso, torna-se importante a utilização de modelos e tipologias que permitam compreender o conteúdo e processo estratégico observado no âmbito organizacional. Partindo dessa perspectiva, este estudo explora o arcabouço teórico formulado por Miles e Snow (1978) em Organizational Strategy, Structure, and Process, trabalho este de reconhecida relevância para o campo de estudos sobre estratégia.

\section{COMPORTAMENTO ESTRATÉGICO: AS TIPOLOGIAS DE MILES E SNOW}

Como exposto na seção anterior, existem diferentes conceitos, quadros teóricos e modelos de análise para a estratégia em organizações. Com efeito, essa diversidade reflete várias tentativas dos autores do campo em compreender e explicar esse fenômeno, gerando implicações tanto para a teoria como para a prática organizacional. Sendo assim, embora se reconheça a existência de outros modelos de análise e sua respectiva importância para o campo de estudos, optou-se, neste trabalho, por explorar o quadro teórico elaborado por Miles e Snow (1978). O emprego desse modelo justifica-se pelo fato dele permitir a identificação de uma série de questões associadas à formação da estratégia, a partir de uma perspectiva mais compreensiva, subjetiva e aprofundada, gerando informações mais densas sobre o comportamento estratégico de organizações. Além disso, embora presente em diferentes contextos organizacionais, tais como pequenas empresas, comércio, indústria e serviços (Gimenez, 1998; Gimenez et al., 1999; Martins et al., 2008; Fagundes \& Gimenez, 2009; Hoffmann, Hoffmann, \& Cancellier, 2009; Almeida, Antonialli, \& Gomes, 2011; Ribeiro, Rossetto, \& Verdinelli, 2011; Soares, Teixeira, \& Pelissari, 2011; Butzke et al., 2012), a adoção do modelo também se justifica por se tratar de um quadro teórico pouco utilizado em pesquisas sobre organizações do setor sucroenergético.

Em seu trabalho, Miles e Snow (1978) esboçaram uma taxonomia de estratégias competitivas, articulando abordagens que assumem um caráter de relação dinâmica entre a organização e o ambiente. Ao elaborar sua teoria de comportamento estratégico, os autores fundamentaram-se em três concepções centrais, as quais colocariam em movimento a dinâmica da estratégia em organizações e sua interação com o ambiente externo. A primeira concepção vincula-se à constatação de que o ambiente se forma e é formado pelas ações organizacionais. A segunda concepção indica que as escolhas estratégicas feitas pela alta administração dão forma à estrutura e aos processos organizacionais. A terceira concepção relaciona-se ao fato de que processos e estrutura condicionam a estratégia. Assim, a relação entre organização e ambiente seria fundamentada a partir de um ciclo adaptativo, envolvendo uma interação dinâmica entre o ambiente, a organização e o agente que percebe a situação organizacional, a incerteza ambiental e os possíveis cursos de ação a serem adotados. Neste sentido, seriam construídas iniciativas de alinhamento estratégico da organização perante o contexto ambiental em que esta se situa (Gimenez et al., 1999; Butzke et al., 2012).

Diante disso, Miles e Snow (1978) identificaram a manifestação de determinados comportamentos estratégicos, que variam de acordo com a dinamicidade do processo de adaptação ao ambiente organizacional, caracterizado por sua complexidade e incerteza. Essa variação advém da percepção que os executivos das organizações têm do ambiente e, com base nelas, como tomam decisões e 
fazem escolhas estratégicas para manterem-nas competitivas (Vieira et al., 2012).

Segundo Miles e Snow (1978), o conteúdo desses comportamentos estratégicos pode ser agrupado em termos de quatro categorias: defensiva, prospectora, analítica e reativa. Essa classificação remete a uma valorização do ambiente, e, ao mesmo tempo, determina o posicionamento da organização com base na interação de fatores e decisões de empresários. Assim, essa tipologia engloba tanto as decisões internas da organização como suas relações com o ambiente externo.

A estratégia defensiva preocupa-se com a estabilidade, a partir do estabelecimento de uma posição do mercado na qual a organização possa exercer domínio. Obtida essa posição, ela é defendida por meio do desenvolvimento de atividades distintas da concorrência. Ao adotar essa estratégia, a organização limita sua área de atuação, reduz a necessidade de investimentos em tecnologia e de ajustes na estrutura operacional. Sua palavra-chave é controle (Giglio \& Onusic, 2013).

A estratégia prospectiva direciona os esforços da organização para a busca ativa e contínua de novas e inovadoras oportunidades no mercado, investindo em pesquisa e desenvolvimento, realizando mudanças em sua área de atuação, bem como criando novos negócios e gerando novos produtos. Nesse tipo de estratégia, contrária ao comportamento defensivo, a empresa renova seus mercados consumidores, abandona produtos em ciclo de vida de maturidade e declínio, age de maneira competitiva e agressiva frente aos concorrentes. Sua palavra-chave seria flexibilidade (Giglio \& Onusic, 2013).

A estratégia analítica constitui um tipo de comportamento estratégico localizado entre a estratégia defensiva e prospectora. A empresa que adota esse tipo de comportamento estaria imersa em dois tipos de mercado, sendo um mais estável e outro mais dinâmico. Nesse caso, é necessário desenvolver um conjunto de produtos e serviços que atenda aos dois mercados. Essa estratégia se aproxima da ideia de imitação criativa, por absorver e melhorar inovações de concorrentes, para até mesmo se proteger e se defender dos competidores. Sua palavra-chave seria equilíbrio (Giglio \& Onusic, 2013).

Por fim, a estratégia reativa seria aquela em que a organização percebe as mudanças no ambiente, mas não consegue estabelecer respostas na velocidade e conteúdo necessárias, devido a dificuldades da administração em articular uma estratégia viável, a dificuldades de acompanhamento em termos de tecnologia, estrutura e processos; e a dificuldades culturais, em que a gestão segue um caminho não mais adequado às condições vigentes do mercado. Assim, as mudanças são efetuadas apenas devido a pressões do ambiente externo. Trata-se, pois, de uma estratégia residual, que surge quando uma das outras três é seguida de maneira inadequada (Giglio \& Onusic, 2013).

Em síntese, a tipologia de Miles e Snow (1978) é estruturada a partir de dois modelos de comportamento iniciais. No primeiro, os gestores agem de acordo com uma perspectiva mais conservadora, focando nos produtos/serviços de maior domínio. No segundo, os exploradores atuam em mercados mais amplos, buscando oferecer novos produtos e serviços independentemente dos resultados. $\mathrm{O}$ analista seria uma junção dos dois primeiros: as organizações mantém uma linha de produtos/serviços estáveis e exploram produtos de sucesso de outras organizações. O reativo, por sua vez, seria aquele tipo de organização só reage quando está ameaçada de perder de clientes ou quando os lucros caem consideravelmente (Mintzberg et al., 2000).

Essa relação entre os tipos de estratégia e o ambiente é o principal conceito no modelo de Miles e Snow (1978). Assim, a tipologia oferecida pelos autores permite compreender o comportamento estratégico de cada organização, a partir da identificação da predominância de um tipo de comportamento específico. Entretanto, deve-se ressaltar que essas tipologias constituem um "tipo ideal”, uma vez que as organizações não assumem puramente um dos tipos de comportamento determinados pela tipologia. $\mathrm{Na}$ prática, o comportamento estratégico é bem mais complexo, fazendo com que a classificação seja realizada em termos de predominância de padrões de comportamento (Soares, Teixeira, \& Pelissari, 2011).

\section{METODOLOGIA}

Neste estudo, efetuou-se uma pesquisa de natureza qualitativa (Godoy, 2013). Para tanto, foi realizado um estudo de caso, voltado para compreender o comportamento estratégico adotado por uma organização do setor sucroenergético brasileiro, a partir das tipologias de Miles e Snow (1978). Yin (2005) define o estudo de caso como uma estratégia de pesquisa que permite a investigação de um fenômeno dentro de seu contexto. Nesse sentido, o estudo de caso qualitativo possibilita a análise de fenômenos sociais com maior profundidade e densidade, revelando evidências importantes para a compreensão e explicação de uma realidade específica, atendendo aos critérios de rigor, validade e confiabilidade (Paiva Jr., Leão, \& Mello, 2011; Oliveira \& Piccinini, 2009). Assim, ressalta-se que não constitui objetivo deste trabalho efetuar discussões mais aprofundadas sobre o seu setor de atuação e efetuar generalizações para outros contextos organizacionais.

O objeto deste estudo foi a Organização Alfa, multinacional atuante nos setores de exploração e produção de petróleo e gás natural, lubrificantes, combustíveis derivados do petróleo, e, mais 
recentemente, produção de etanol. O caso da Organização Alfa foi selecionado a partir do critério de acessibilidade e, principalmente, pela sua relevância e idiossincrasia no âmbito do setor sucroenergético. Cabe ressaltar que a investigação foi realizada no período entre novembro de 2012 e fevereiro de 2013. O nome da organização e dos sujeitos de pesquisa foram suprimidos, de modo a garantir o sigilo das informações coletadas.

Como técnicas para coleta de dados, foram utilizadas a pesquisa documental e a entrevista (Triviños, 1987). Primeiramente, por meio da pesquisa documental, foram consultados dados secundários em publicações de instituições relacionadas ao setor sucroenergético brasileiro, bem como em notícias de jornais, revistas, páginas da internet e artigos que abordaram tanto o setor como a organização estudada. Os dados coletados permitiram compreender as trajetórias da indústria sucroenergética e da Organização Alfa, possibilitando interessante contextualização da pesquisa. Além disso, também foram utilizados documentos e comunicados internos, clippings e material publicado no sítio da organização estudada, de modo a complementar o corpus textual necessário para o cumprimento dos objetivos da pesquisa.

Posteriormente, foram realizadas entrevistas em profundidade junto a três diretores da principal unidade de produção de etanol da organização estudada, sendo dois diretores administrativos e um diretor da área agrícola. O critério para seleção dos sujeitos entrevistados envolveu, basicamente, a questão da disponibilidade, da relevância para o contexto da pesquisa, bem como a vivência de experiências práticas relacionadas à atuação estratégica da organização. As entrevistas foram orientadas por meio de um roteiro semiestruturado, e tiveram duração média de 90 minutos, tendo sido gravadas e transcritas para que fosse possível resgatar seu inteiro teor, e assim permitir exprimir com fidelidade as colocações dos respondentes. Acredita-se que, apesar do número reduzido de entrevistas, foi possível apreender todas as especificidades associadas ao comportamento estratégico da organização estudada, uma vez que os entrevistados são os principais responsáveis pela estratégia da unidade da empresa em questão. Além disso, foi levado em consideração o critério de saturação dos dados, uma vez que, ao longo das entrevistas, houve repetição de informações e opiniões sobre os tópicos investigados.

Para complementar os dados das entrevistas, foi utilizado um questionário fechado, conforme elaborado por Conant et al. (1990) e adaptado por Gardelin (2010), composto de onze perguntas sobre aspectos ligados à tipologia de Miles e Snow (1978), com o objetivo de classificar as estratégias utilizadas pela organização. Os aspectos abordados nas questões foram os seguintes: produtos e serviços oferecidos; imagem que a empresa possui no mercado; tempo gasto em relação ao monitoramento das mudanças e tendências; aumento, manutenção ou diminuição dos clientes; objetivos e metas importantes; habilidades e competências profissionais; fatores que mais influenciaram na manutenção do seu negócio; foco dos gestores; futuro da empresa; estrutura organizacional; e processos de controle e tomada de decisões adotadas (Conant et al., 1990; Gardelin, 2010).

Quanto à análise de dados, foi utilizada a técnica de análise de conteúdo. Essa técnica visa identificar o que está sendo dito em relação a determinado tema (Bardin, 2004). Foram categorizadas duas temáticas principais: a entrada da empresa no setor sucroenergético brasileiro e os diferentes comportamentos estratégicos resultantes de sua atuação no mercado. Essas categorias, por sua vez, são consistentes com os objetivos da pesquisa, revelando evidências interessantes sobre as estratégias da organização estudada.

\section{CONTEXTO DA PESQUISA: O SETOR SUCROENERGÉTICO BRASILEIRO}

O Brasil é um dos maiores produtores mundiais de etanol à base de cana-de-açúcar (Matias et al., 2013). A utilização do etanol como fonte alternativa de energia no país tem início no século XX, por meio de medidas instituídas pelo Estado e instituições privadas, indústria automobilística, refinarias e usineiros, começaram. O Brasil, que possuía diversas características para assumir esse pioneirismo, como disponibilidade de mão de obra, áreas para plantio e clima favorável, iniciou uma série de programas de incentivo, dentre os quais se destaca o Programa Nacional do Álcool (Proálcool), que visava incentivar a produção e o consumo do etanol (Piacente, 2006).

No final dos anos 80, a crescente demanda pelo álcool, os altos preços do açúcar no mercado internacional, e o fim dos subsídios para a produção de etanol, levaram a um desabastecimento do produto no mercado brasileiro. Essa situação gerou uma forte crise do Proálcool e uma desconfiança geral por parte dos consumidores (Shikida et al., 2011).

Após esse período de crise, a década de 90 representou um marco para o mercado de etanol, a partir do início de um processo de consolidação da indústria. Nesse período, houve um processo de desregulamentação, caracterizado pela diminuição da intervenção estatal no setor. Esse contexto contribuiu para que as organizações buscassem maiores níveis de competitividade, por meio da realização de investimentos, da busca por técnicas administrativas e de produção mais eficientes, e por ações de associativismo, como a criação da UNICA - União da Indústria de Cana-de-Açúcar (Mesquita \& Oliveira, 2008).

A partir dos anos 2000, a indústria de etanol vivenciou um período de crescimento, posicionando o Brasil como um dos maiores produtores mundiais de 
Comportamento Estratégico: Estudo de Caso em uma Organização do Setor Sucroenergético Brasileiro

biocombustível. Em 2003, surgiram novas alternativas tecnológicas para o uso do etanol, principalmente com a introdução dos automóveis flex-fuel (Mesquita \& Sugano, 2011; Matias et al., 2013). A partir de 2007, houve o início de um forte movimento de consolidação do setor. A crise econômica de 2008 abriu espaço para a entrada de multinacionais no setor, a partir de processos de fusão e aquisição (Siqueira \& Castro Júnior, 2010). Essa problemática existente no setor se configura como um desafio do ponto de vista estratégico para as organizações. Na seção seguinte, serão apresentados e discutidos os resultados da pesquisa, com o intuito de compreender como se deu a entrada da Organização Alfa no setor sucroenergético e a configuração de seu comportamento estratégico, a partir das tipologias de Miles e Snow.

\section{COMPORTAMENTO ESTRATÉGICO NO SETOR SUCROENERGÉTICO: O CASO DA ORGANIZAÇÃO ALFA}

Este tópico possui o objetivo de apresentar e discutir os resultados da pesquisa de campo. Em um primeiro momento, procurou-se resgatar as características principais do processo de entrada da Organização Alfa no setor sucroenergético brasileiro. Para tanto, ele foi construído com base na pesquisa documental feita a partir de dados secundários, como documentos e comunicados internos, clippings, notícias de jornais e revistas, e artigos publicados no site da Organização Alfa, e nas entrevistas com os diretores da unidade estudada. Em um segundo momento, procurou-se analisar o comportamento estratégico da empresa estudada, com base nas entrevistas junto aos diretores da unidade investigada e nos resultados obtidos por meio da aplicação do questionário estruturado, voltado para a identificação do posicionamento dos respondentes frente às tipologias propostas por Miles e Snow (1978).

\subsection{A entrada da Organização Alfa no setor sucroenergético brasileiro}

A Organização Alfa atua no Brasil em diversos segmentos: exploração e produção de petróleo e gás natural, produção de combustíveis derivados do petróleo, e, mais recentemente, produção de etanol. Em meados da década de 2000, a empresa tornou-se uma das primeiras companhias de capital aberto a investir no etanol brasileiro de cana-de-açúcar. A entrada da Organização Alfa no setor sucroenergético deu-se por meio de um processo de aquisição de usinas brasileiras de produção de etanol e açúcar. Esse processo caracterizou-se pela aquisição de participação acionária de usinas situadas nas regiões Sudeste e Centro-Oeste. Posteriormente, em 2011, a Organização Alfa passou a ser detentora de $100 \%$ do capital dessas empresas, consolidando, assim, sua atuação no setor sucroenergético brasileiro.

A escolha pelo Brasil justificou-se dada a condição do país enquanto maior produtor de cana-deaçúcar do mundo. O destaque nacional deve-se às condições favoráveis de clima e solo, à existência de uma demanda crescente de produtos derivados da cana, e à existência de um importante potencial para a expansão da atividade, seja por meio de ampliação da área plantada, seja a partir de avanços tecnológicos voltados para o aumento da produtividade:

O Brasil tem hoje uma economia crescente, com baixos riscos macroeconômicos e a alta lucratividade no negócio, alem de ser um mercado que possui um déficit muito grande de oferta. Hoje o Brasil importa álcool para o mercado interno (Entrevistado A).

A motivação está no fato do Brasil, além de ser o maior produtor mundial de açúcar e álcool, e possuir todas as condições pra que isso ocorra, é também um dos países mais experientes, com anos e anos de cultivo. Há o fato ainda de que o Brasil possui a maior área agricultável, comparado a outros países, e sendo que nem $10 \%$ dessa área é realmente utilizada (Entrevistado C).

Conforme exposto pelos entrevistados, o Brasil apresenta características favoráveis ao cultivo e produção dos produtos derivados da cana-de-açúcar. As regiões de Cerrado do Sudeste e Centro-Oeste (onde estão instaladas as usinas do grupo) constituem a principal área de expansão do setor sucroalcooleiro do país, revelando oportunidades de negócio a serem exploradas pela organização. Cabe ressaltar, ainda, que, segundo os entrevistados, a opção pela produção de biocombustíveis apresenta-se como um movimento estratégico da empresa no setor de energia. Existem estimativas de um aumento da demanda global por energia em pelo menos $50 \%$ nos próximos 20 anos, impulsionada pelo crescimento populacional e pela rápida industrialização das economias emergentes. Nesse sentido, há um incremento importante de investimentos no setor, marcado pela ampliação da política de incentivos para a produção de biocombustíveis, e pela expectativa de retomada do consumo de etanol no mercado interno e no potencial do mercado externo. A organização, por sua vez, aproveita-se da frágil situação financeira de usineiros locais, empreendendo movimentos de fusão e aquisição e, assim, aumentando sua participação no mercado brasileiro. Em segundo lugar, oportunidades de negócio como a existência de incentivos fiscais, a diversidade de crédito e de fontes de financiamento, a rapidez na liberação de licenças ambientais, e a posição geográfica estratégica, com a proximidade dos grandes centros de consumo e de exportação, fazem com que a Organização Alfa intensifique seus investimentos no Brasil. 
Adicionalmente, os entrevistados apontam que os investimentos em energia limpa demonstram uma preocupação da organização com a busca por sustentabilidade:

A preocupação em si é com energias renováveis, a empresa se preocupa com o meio ambiente e quer novas fontes de energias renováveis para um futuro próximo (Entrevistado A).

Primeiramente devido à busca da tão famosa sustentabilidade, pois além de segurança, as empresas que estão no mercado mundial, sabem que para se manterem, precisam de renovações sustentáveis, como tecnologia avançada e matérias-primas renováveis. Já que a preocupação mundial se deve aos riscos ambientais, conflitos culturais (Entrevistado C).

A partir desse viés de sustentabilidade, quando questionados sobre a influência dos impactos ambientais da produção de petróleo e gás, além da entrada da empresa no mercado de energias renováveis, os entrevistados apontaram como objetivo principal a necessidade de construção de uma imagem positiva em relação ao posicionamento socioambiental da empresa:

Acredito que a [Alfa] viu no biocombustível uma oportunidade pra mudar a visão pessimista que muitos ainda podem ter. Até uma questão de estratégia de mercado. Onde poderá produzir outros tipos de 'energia limpa' e gerar confiança dos países de suas 'joint ventures' ou de futuras instalações (Entrevistado B).

Como pode ser observado no relato acima, os investimentos da organização em energia limpa fazem parte de uma estratégia que visa gerar credibilidade e estabelecer uma imagem positiva quanto às questões socioambientais. Além disso, o movimento na direção da energia limpa se torna uma dupla estratégia: de um lado, permite a (re)construção da imagem e do discurso de sustentabilidade e de responsabilidade ambiental da empresa; de outro, permite a entrada da organização em um novo mercado, acesso a novas fontes de energia e a novas tecnologias, configurando uma nova estratégia de atuação no mercado que, no longo prazo, pode se mostrar como um investimento promissor.

A partir desse contexto, o posicionamento da organização no mercado pode ser identificado a partir de tentativas de se criar um diferencial eficaz para seus produtos e serviços, garantindo assim uma maior competitividade da empresa frente à concorrência:

A empresa não está muito preocupada com a concorrência, o mercado é um mercado que está em falta, tudo que você produzir você coloca. A preocupação da empresa nesse momento é produzir com qualidade e produzir mais. Esse é o meu ponto de vista. A empresa se posiciona no mercado da melhor forma possível, ela quer ser líder de mercado, de forma segura e consciente (Entrevistado A).

Hoje a [Alfa] procura adequar as condições de produção para aumento de produtividade, visando, em primeiro lugar, a segurança dos seus funcionários. A modernização, tecnologia e pesquisas desenvolvidas tem papel fundamental pra melhorar a qualidade de produção, ou seja, diminuindo os custos a longo prazo e aumentando a produtividade. Posteriormente, muitos dos projetos desenvolvidos serão de suma importância para a diversificação de produtos (Entrevistado B).

Os relatos acima demonstram que a organização não está preocupada com a concorrência, e, sim, em adequar as suas condições de produção e tecnologia para obter aumento de produtividade. Nesse sentido, com o objetivo estratégico claro de tornar-se a empresa líder do mercado, a Organização Alfa, posiciona-se, de certa forma, despreocupada com a concorrência. Tal postura pode ser explicada na medida em que a organização insere-se em um setor caracterizado por uma demanda parcialmente atendida, implicando em uma necessidade de aumento da produção e da produtividade. Para tanto, a organização tem estruturado estratégias específicas para alcançar esses objetivos: investimentos em tecnologia; ampliação das áreas de plantio de cana; melhoria dos métodos de produção (tanto no campo como na usina); implantação de técnicas avançadas de gestão; e qualificação de mão-de-obra.

Em relação a possíveis movimentos futuros, observa-se que há uma valorização, no âmbito da Organização Alfa, da identificação de condições que conduzam à ampliação de sua capacidade produtiva e a maiores ganhos de produtividade, uma vez que o setor sucroenergético apresenta uma perspectiva de demanda crescente em etanol. Para tanto, a organização tem promovido alguns movimentos no sentido dessa estratégia de crescimento, buscando quadruplicar sua produção de cana-de-açúcar no Brasil até 2017, por meio de investimentos em novas áreas plantadas (greenfields), da expansão das atuais unidades industriais e de processamento existentes, e do aumento de produtividade. Em entrevista publicada no site da Organização Alfa, o Presidente da unidade brasileira afirma que a empresa tem trabalhado fortemente na melhoria da sua eficiência operacional e está em busca de oportunidades de crescimento. Nesse sentido, a ampliação da capacidade instalada da indústria representa um marco significativo em sua estratégia de atuação no mercado de biocombustíveis e reforça seu compromisso com o setor. Além disso, conforme identificado nas entrevistas com os diretores, é de interesse da organização que o projeto de ampliação da capacidade produtiva envolva usinas já 
instaladas e novas unidades industriais, a serem criadas na região do cerrado brasileiro.

Portanto, a entrada da Organização Alfa no mercado sucroenergético brasileiro deu-se de uma forma gradativa. No início, tal estratégia envolveu a aquisição de participações de grupos e empresas do setor, com a formação de parcerias e sociedades que possibilitaram um maior conhecimento em relação às especificidades da indústria. Em um segundo momento, a organização optou por adquirir a totalidade das empresas e tornar-se controladora destas. A partir desse momento, a Organização Alfa tem efetuado investimentos de ordem significativa em tecnologia e inovação, com o objetivo principal de melhorar a sua produtividade e, assim, o alcançar a liderança do mercado brasileiro.

\subsection{Comportamento estratégico: classificação da estratégia da Organização Alfa conforme as tipologias de Miles e Snow.}

Neste tópico, serão apresentados e discutidos os resultados relacionados ao comportamento estratégico da Organização Alfa, a partir das tipologias de Miles e Snow (1978). Para tanto, os respondentes apresentaram suas opiniões com base em um questionário, apresentado por Conant et al. (1990) e adaptado por Gardelin (2010), o qual permite classificar as estratégias utilizadas pelos gestores e tipificar o posicionamento estratégico da organização. Nesse questionário, foram apresentadas onze questões, cada uma com quatro alternativas de resposta, tendo o respondente a tarefa de indicar a alternativa que mais se aproxima com a realidade da Organização Alfa, e comentar, qualitativamente, sobre os motivos que permitem explicar o posicionamento da empresa, a partir de suas respostas.

A primeira pergunta refere-se à caracterização dos produtos e serviços oferecidos aos clientes. Nesse quesito, segundo os respondentes, o conjunto de produtos e serviços oferecidos não é amplo e não sofre muitas modificações, porém são bem focados para atender determinadas demandas do mercado. Esse tipo de postura revela um comportamento prospector, na medida em que a Organização Alfa trabalha com um conjunto restrito de produtos, tais como o açúcar, o álcool anidro (aditivo para a gasolina), álcool hidratado, e eletricidade excedente do processo industrial, cogerada na queima de bagaço e palha da cana-de-açúcar. $\mathrm{O}$ foco desses produtos encontra-se voltado, por sua vez, para o atendimento do excedente de demanda existente no mercado, fato que direciona a preocupação estratégica da organização para a busca de aumento da produtividade.

A segunda questão refere-se à imagem que a organização passa para seus clientes. Nesse aspecto, os respondentes associaram o posicionamento da Organização Alfa a um comportamento analista (ora prospector, ora defensivo). Tal comportamento pode ser explicado na medida em que, por um lado, a organização sempre buscou adotar novas ideias, novas práticas e inovações, agregando-as a seus produtos e serviços; e por outro lado, antes da adoção dessas novas práticas e inovações, é feita uma análise criteriosa de seus custos e suas implicações estratégicas e financeiras. Assim, verifica-se a existência, em um primeiro momento, de um perfil prospector, que pode ser observado a partir da entrada da Organização Alfa no mercado de energia limpa, constituindo uma inovação em seu portfólio ligado aos produtos baseados em petróleo. Em um segundo momento, porém, verifica-se uma postura defensiva, uma vez que a organização estuda detalhadamente cada nova estratégia, como pode ser observado em sua decisão de atuar com um produto já estabelecido (etanol de canade-açúcar) e de fácil aceitação no mercado brasileiro.

A terceira pergunta permite apreender a postura da empresa em relação ao tempo gasto com o monitoramento das mudanças e tendências. As respostas indicaram um comportamento prospector, uma vez que a organização gasta tempo considerável em atividades de análise e interpretação do mercado e do ambiente externo. Esse posicionamento pode ser exemplificado, no caso da Organização Alfa, por meio de iniciativas de revisão e constante análise do portfólio de ativos (greenfields), e de ajustes estratégicos dos projetos voltados para o crescimento da capacidade produtiva da empresa.

A quarta questão, relacionada ao aumento, manutenção e/ou eventual diminuição do número de clientes, indicou a presença de um comportamento analítico. A postura organização neste quesito revela uma atuação mais centrada em mercados já estabelecidos, com a busca por novos mercados empreendida somente após análise cuidadosa de seu potencial. Tal comportamento reforça o posicionamento exposto na questão anterior, uma vez que a organização estudada busca estabelecer novos produtos e serviços e explorar novos mercados somente após um considerável período de análise de cenários e de viabilidade de investimento, bem como após o monitoramento do ambiente e do mercado como um todo.

A quinta pergunta, que procura elucidar sobre o tipo de enfoque estratégico da empresa, evidenciou um comportamento defensivo. Para os respondentes, a meta mais importante da organização consiste em concentrar esforços e ter disciplina em manter os custos sobre controle, dedicando atenção especial à melhoria da eficiência das operações vigentes. Esse posicionamento revela que, para a Organização Alfa, as questões operacionais podem ser mais importantes do que outros aspectos, tais como diferenciação e inovação, uma vez que a empresa opera em um setor com poucos concorrentes.

A sexta questão procura caracterizar as habilidades e competências da empresa. Neste caso, não houve um consenso nas respostas, tendo a 
organização: a) características analíticas, em que as habilidades e competências capacitam os profissionais a identificar as tendências do mercado e possibilidades de desenvolvimento de novos produtos e serviços; b) características especialistas, em que as habilidades e competências encontram-se concentradas em uma ou poucas áreas específicas; e c) características amplas e empresariais, em que as habilidades e competências são diversas e flexíveis, capacitando a organização a mudar e ser produtiva. Essa divisão, portanto, remete aos comportamentos analítico, defensivo e prospector, permitindo caracterizar o comportamento estratégico da organização neste quesito como um comportamento analítico. Como exposto por Miles e Snow (1978), o comportamento analítico é a união dos posicionamentos prospectores e defensivos. Na prática, de um lado, a empresa atua prospectando o ambiente, tendo habilidades e competências para buscar alternativas estratégicas de atuação no mercado, e de outro, mantendo uma concentração dessas habilidades e competências em atividades específicas, voltadas exclusivamente para sua área de atuação.

A sétima pergunta possibilita apreender os fatores que mais influenciam na manutenção do negócio. As respostas indicaram um comportamento analítico, estruturado a partir de análise hábil e cuidadosa das tendências de mercado e posterior adoção de práticas e estratégias que possuíam, comprovadamente, potencial. A organização revela essa postura analítica na medida em que seus investimentos na atividade de produção de etanol de cana-de-açúcar são baseados: na aquisição de usinas e áreas plantadas já consolidadas; em um processo/produto já consolidado no mercado brasileiro; e no nível de desenvolvimento tecnológico desse tipo de combustível em comparação a outras fontes energia renovável e ecológica desenvolvidas. Assim, a empresa revela seu comportamento analítico, uma vez que atua ora prospectando o ambiente em busca de novas oportunidades de negócio, ora defendendo sua posição no mercado competitivo.

A oitava questão, voltada para a análise da postura de ação e decisão dos gestores, revelou a presença de um comportamento reativo, estando os administradores (líderes) centrados em cuidar, de forma isolada, das atividades internas e dos negócios da empresa. Esse tipo de comportamento, caracterizado como residual, pode ser justificado pelo fato de que a área de biocombustíveis constitui um novo negócio no âmbito da Organização Alfa, o que, por sua vez, indica a necessidade de se estudar, avaliar, analisar, e se preparar para melhor compreender esse ramo de atividade. Segundo os respondentes, há um movimento atual de se buscar um maior conhecimento sobre as especificidades do mercado sucroenergético brasileiro, de modo a aperfeiçoar suas operações e a consolidar suas atividades antes de expandir seus negócios, em uma tentativa de manter uma posição segura no mercado para, assim, iniciar de fato seu crescimento e sua expansão.
A nona pergunta, relacionada ao futuro da empresa, permitiu observar características de comportamento analítico, associado a movimentos de análise e identificação de tendências de mercado com potencial comprovado, sem contudo deixar de se preocupar com a busca por solução de problemas atuais. Nesse sentido, de acordo com os respondentes, a Organização Alfa procura empreender inovações de produtos e buscar novos mercados, a partir de uma análise criteriosa dos meios necessários para a exploração dessas oportunidades e comercialização confiável de seus produtos. Paralelamente, ao mesmo tempo em que a organização gera novos produtos, há também uma preocupação com os problemas atuais e futuros, fato que demanda constante avaliação dos resultados obtidos para possibilitar melhorias em suas atividades operacionais.

A décima questão, a qual caracteriza a estrutura organizacional da empresa como claramente separada em setores específicos, que seguem corretamente a hierarquia, revelou a existência de um comportamento defensivo. A cultura nacional de origem da Organização Alfa, marcada por aspectos de natureza burocrática, constitui-se como um fator que explica esse tipo de estrutura adotada pela empresa. A vantagem desse tipo de estrutura encontra-se associada a uma especialização técnica, permitindo uma eficiente utilização dos recursos em cada área, e facilitando o monitoramento e controle dessa utilização. Porém, o excesso de especialização pode levar à perda da visão sistêmica do todo, limitando possibilidades de identificação de oportunidades de mercado.

A última pergunta busca caracterizar os processos de controle e tomada de decisões adotadas pela empresa. Verificaram-se características analistas, defensivas e reativas, não sendo possível afirmar que exista um tipo predominante de comportamento estratégico, associado aos processos de controle e tomada de decisões. As respostas revelaram posturas ora descentralizadas, com decisões voltadas para a solução de problemas; e ora centralizadas, em que o controle está principalmente relacionado a vários relatórios utilizados para analisar riscos e resultados, descartando o comportamento descentralizado e participativo, o que limita a representatividade na elaboração, operação e gestão da empresa.

O conjunto de respostas obtidas torna possível a identificação de um padrão de comportamento híbrido, variando entre prospector e analítico. Esse padrão permite supor que o comportamento estratégico da empresa determina seu posicionamento no mercado, caracterizando a empresa a partir de uma dupla estratégia: ora prospectando o ambiente e o setor competitivo, introduzindo uma perspectiva inovadora em sua atuação interna e externa; ora analisando esses contextos internos e externos na busca de uma inserção no mercado local e internacional mais efetiva. Assim, tem-se a configuração de um comportamento estratégico que explica, pelo menos em partes, a 
estratégia da Organização Alfa em sua atuação no mercado sucroenergético brasileiro.

\section{CONSIDERAÇÕES FINAIS}

O objetivo do presente trabalho consistiu em compreender o comportamento estratégico de uma organização do setor sucroenergético brasileiro. A realização da pesquisa permitiu descrever como ocorreu o processo de entrada da empresa no setor sucroenergético brasileiro e compreender o comportamento estratégico da organização, a partir da aplicação da tipologia de Miles e Snow (1978).

Em um primeiro momento, verificou-se que essa entrada ocorreu de forma gradativa. Esse movimento foi caracterizado, inicialmente, por iniciativas de aquisição de participações de grupos e empresas do ramo. Em seguida, a organização optou por adquirir a totalidade dessas empresas e tornar-se a sua controladora. Para se consolidar no mercado, a organização tem realizado fortes investimentos em tecnologia e em eficiência operacional, a fim de aumentar a capacidade produtiva e melhorar a produtividade. Pode-se observar, ainda, que a Organização Alfa possui como objetivos estratégicos o alcance da liderança de mercado, o aproveitamento de oportunidades presentes no mercado local e internacional, bem como a realização de investimentos em tecnologia, ampliação das áreas de plantio de cana, melhoria dos métodos de produção, melhoria da gestão e qualificação de mão de obra.

Por fim, a partir da aplicação da tipologia de Miles e Snow (1978), foi identificado um padrão de comportamento híbrido. Esse tipo de comportamento, condizente com os pressupostos do quadro de análise elaborado pelos autores, revelou variações entre uma postura prospectora, baseada na busca por novas oportunidades de mercado, na criação de mudanças e inovações, na operação em novos mercados e nos investimentos em tecnologia para o desenvolvimento de novos produtos, assumindo riscos ao longo desse processo; e em uma postura analítica, quando divide suas operações entre iniciativas que visam, ao mesmo tempo, a estabilidade (a partir da valorização das rotinas e da eficiência em processos) e a mudança (a partir da busca constante por novas ideias, produtos e tecnologias).

Portanto, conclui-se que a Organização Alfa tem um posicionamento hibrido, sendo analista o seu

\section{REFERÊNCIAS}

Almeida, I. C., Antonialli, L. M., \& Gomes, A. F. (2011). Comportamento estratégico de mulheres empresárias: estudo baseado na tipologia de Miles e Snow. Revista Ibero-Americana de Estratégia, 10(1), 102-127. doi: 10.5585/riae.v10i1.1706 posicionamento estratégico predominante. Porém, o comportamento prospector apareceu de forma significativa quanto a vários aspectos analisados, o que caracteriza o posicionamento da empresa no mercado a partir de uma dupla estratégia, ora prospectando o ambiente e o setor competitivo, introduzindo uma perspectiva inovadora tanto em sua atuação interna como em sua intervenção externa, ora analisando o setor, o ambiente, perspectivas de demandas, estratégias e outras oportunidades de mercado.

Além disso, ao retomar as já difundidas tipologias de Miles e Snow (1978), foi possível identificar a definição do posicionamento estratégico adotado pela Organização Alfa, apresentando uma tendência de perfil estratégico a ser seguido de acordo com as decisões tomadas. Sendo assim, apesar de já ter sido explorada em outros contextos de investigação nos estudos em estratégia, a referida tipologia apresenta-se como importante instrumento de pesquisa para a análise e adoção de determinados posicionamentos estratégicos e para a tomada de decisão, sobretudo no caso analisado, mostrando-se assim como quadro de referência para a realização de estudos que procurem compreender a realidade estratégica organizacional.

Este trabalho transmite implicações interessantes ao campo de pesquisas sobre estratégia e administração estratégica. Do ponto de vista teórico, este estudo contribui para identificação de novas evidências teóricas vinculadas ao modelo proposto por Miles e Snow (1978). Essas evidências estariam associadas à possibilidade de se preocupar menos com a categorização em si e mais com a compreensão do comportamento estratégico de organizações, realçando aspectos mais subjetivos acerca desses comportamentos. Do ponto de vista metodológico, este estudo contribui com a formulação de novos delineamentos de pesquisa envolvendo a aplicação do modelo, uma vez que sua adoção no âmbito de pesquisa qualitativa tem sido pouco explorada pelos pesquisadores da área. Não obstante, sugere-se que estudos futuros explorem outras possibilidades metodológicas que podem ser vinculadas ao modelo de Miles e Snow (1978), tais como estudos multicasos ou ainda pesquisa quantitativa aplicada especificamente às diferentes organizações que compõem o setor sucroenergético brasileiro, fazendo avançar os resultados aqui apresentados.

Augusto, C. A., Takahashi, L. Y., \& Sachuk, M. Y. (2012). A influência da inovação tecnológica na competitividade e nas relações de trabalho em usinas de açúcar e álcool paranaenses. 
Organizações Rurais \& Agroindustriais, 14(1), 114.

Barbosa, M. F. N., \& Cândido, G. A. (2013). Competitividade em organizações agroindustriais: aplicação metodológica em empresa do setor sucroalcooleiro no estado da Paraíba. Gestão \& Regionalidade, 29(86), 61-76.

Bardin, L. (2004). Análise de conteúdo. 3. ed. Lisboa: Edições 70.

Bertero, C. O., Vasconcelos, F. C., \& Binder, M. P. (2003). Estratégia Empresarial: a produção científica brasileira entre 1991 e 2002 . Revista de Administração de Empresas, 43(4), 48-62.

Borges, A. F., Freitas Junior, D. B., \& Oliveira, E. R. (2008). Estratégia e Administração Pública: o caso do Programa "Choque de Gestão" do Governo do Estado de Minas Gerais. Revista Pretexto, 9(3), 79106.

Bulgacov, S. et al. (2007). Administração estratégica: teoria e prática. São Paulo: Atlas, 2007.

Butzke, M. A., Lang, J., Marinho, S. V., Alberton, A. (2012, setembro). A Percepção do Ambiente Organizacional e Comportamento Estratégico de Gestores de IES. Anais do Encontro da Associação Nacional de Pós-Graduação e Pesquisa em Administração, Rio de Janeiro, RJ, Brasil, 36.

Colla, J. E., Martins, T. S., \& Kato, H. T. (2012, setembro). A Produção Científica em Estratégia entre os anos 2000 e 2010. Anais do Encontro da Associação Nacional de Pós-Graduação e Pesquisa em Administração, Rio de Janeiro, RJ, Brasil, 36.

Conant, J. S., Mokwa, M. P., \& Varadarajan, P. R. (1990). Strategic types, distinctive marketing competencies and organizational performance: a multiple measures-based study. Strategic Management Journal, 11(5), 365-383. doi: 10.1002/smj.4250110504

Fagundes, F. M., \& Gimenez, F. A. P. (2009). Ambiente, estratégia e desempenho em micro e pequenas empresas. Revista Brasileira de Estratégia, 2(2), 133-146.

Feltre, C., \& Paulillo, L. F. O. (2013). A pluralidade nas transações de cana-de-açúcar no oeste paulista. Revista de Administração Contemporânea, 17(6), 661-678.

Furrer, O., Thomas, H., \& Goussevkaia, A. (2008). The structure and evolution of the strategic management field: a content analysis of 26 years of strategic management research. International Journal of
Management Reviews, 10(1), 1-23. doi: 10.1111/j.1468-2370.2007.00217.x

Gardelin, J. P. (2010). O comportamento estratégico e a percepção de incerteza e munificiência de micro e pequenas empresas. (Dissertação de Mestrado). Universidade do Vale do Itajaí, Biguaçú, SC, Brasil.

Giglio, E. M., \& Onusic, L. M. (2013). Revalorização do modelo de Miles: lições das teorias de redes para decisões estratégicas. Revista Eletrônica de Administração, 19(1), 192-218.

Gimenez, F. A. P. (1998). Escolhas estratégicas e estilo cognitivo: um estudo com pequenas empresas. Revista de Administração Contemporânea, 2(1), 27-45. doi: 10.1590/S1415-65551998000100003

Gimenez, F. A. P., Pelisson, C., Krüger, E. G. S., \& Hayashi Jr, P. (1999). Estratégia em pequenas empresas: uma aplicação do modelo de Miles e Snow. Revista de Administração Contemporânea, 3(2), 53-74. doi: 10.1590/S141565551999000200004

Godoy, A. S. (2013). Fundamentos da Pesquisa Qualitativa. In TAKAHASHI, A. R. W. (Org.). Pesquisa Qualitativa em Administração: fundamentos, métodos e uso no Brasil (Vol. 1, cap. 3, pp. 35-50). São Paulo: Atlas.

Hoffmann, R. A., Hoffmann, V. E., \& Cancellier, E. L. P. L. (2009). As estratégias da microempresa varejista e seus estágios de informatização. Revista de Administração Mackenzie, 10(2), 110-134. doi: 10.1590/S1678-69712009000200006

Martins, T. S., Cruz, J. A. W., Kato, H. T., Reis, J. A., \& El-kouba, A. (2008). A influência da tipologia estratégica de Miles e Snow no grau de orientação para o mercado em instituições de Ensino Fundamental e Médio do Estado do Paraná. Revista Ibero-Americana de Estratégia, 7(2), 125-137.

Matias, C. A., Souza, G., Figueiredo, P. (2013). Coevolution of institutional frameworks and technological capability building across different industrial regimes: the ethanol industry in Brazil. Journal for Global Business and Communitiy, 4(1), 65-80.

Mesquita, D. L., \& Oliveira, E. R. de. (2008). As reformas liberais da década de 90: as políticas da "Terceira Via" e o novo ambiente institucional no setor sucroalcooleiro brasileiro. Anais do Encontro da Associação Nacional de Pós-Graduação e Pesquisa em Administração, Rio de Janeiro, RJ, Brasil, 32. 
Mesquita, D. L., \& Sugano, J. Y. (2011). The flex fuel technology building process in Brazil: An analysis from the perspective of business platform. African Journal of Business Management, 5(20), 81008109. doi: 10.5897/AJBM11.006

Miles, R. E., \& Snow, C. C. (1978). Organizational Strategy, Structure, and Process. New York: McGrall-Hill.

Mintzberg, H., Ahlstrand, B., \& Lampel, J. (2000). Safári de estratégia: um roteiro pela selva do planejamento estratégico. Porto Alegre: Bookman.

Mintzberg, H., Lampel, J., Quinn, J., \& Ghoshal, S. (2006). O Processo da Estratégia: conceitos, contextos e casos selecionados. 4 ed. Porto Alegre: Bookman.

Nag, R., Hambrick, D. C., \& Chen, M. J. (2007). What is strategic management, really? Inductive derivation of a consensus definition of the field. Strategic Management Journal, 28(9), 935-955. doi: 10.1002/smj.615

Oliveira, S. R., \& Piccinini, V. C. (2009). Validade e reflexividade na pesquisa qualitativa. Cadernos EBAPE.BR, 7(1), 88-98. doi: 10.1590/S167939512009000100007

Paiva Júnior, F. G., Leão, A. L. M. S., \& Mello, S. C. B. (2011). Validade e Confiabilidade na Pesquisa Qualitativa em Administração. Revista de Ciências da Administração, 13(31), 190-209.

Piacente, E. A. (2006). Perspectivas do Brasil no mercado internacional de etanol. (Dissertação de Mestrado). Universidade Estadual de Campinas, Campinas, SP, Brasil.

Ribeiro, R., Rossetto, C. R., \& Verdinelli, M. A. (2011). Comportamento estratégico da empresa e a visão baseada em recursos: um estudo no setor varejista de material de construção. Gestão \& Produção, 18(1), 175-192. doi: 10.1590/S0104530X2011000100013

Ronda-Pupo, G., \& Guerras-Martin, L. (2012). Strategic Management Journal, 33(2), 162-188. doi: 10.1002/smj.948
Shikida, P. F. A., Azevedo, P. F. de, \& Vian, C. E. de F. (2011). Desafios da agroindústria canavieira no Brasil pós-desregulamentação: uma análise das capacidades tecnológicas. Revista de Economia e Sociologia Rural, 49(3), 599-628. doi: 10.1590/S0103-20032011000300004

Siqueira, P. H. de L., \& Castro Junior, L. G. de. (2010). Fusões e aquisições das unidades produtivas e da agroindústria de cana-de-açúcar no Brasil e nas distribuidoras de álcool hidratado etílico. Revista de Economia e Sociologia Rural, 48(4), 709-735. doi: 10.1590/S0103-20032010000400009

Soares, M. C., Ramos, H. R., Etchebarne, M. S., \& Geldres, V. (2011). Estrutura organizacional e internacionalização de empresas: um estudo de caso no Setor Sucroenergético do Brasil. Revista IberoAmericana de Estratégia, 10(3), 49-65. doi: 10.5585/riae.v10i3.1780

Soares, M. L., Teixeira, O. R. P., \& Pelissari, A. S. (2011). Comportamento Organizacional: uma Aplicação da Tipologia de Miles e Snow no Setor Hoteleiro de Florianópolis-Sc. Revista de Administração da UFSM, 4(2), 251-267.

Triviños, A. N. S. (1987). Introdução à pesquisa em ciências sociais: a pesquisa qualitativa em educação. São Paulo: Atlas.

União Da Indústria De Cana-De-Açúcar (2012). Canade-açúcar no Brasil. Recuperado em <www.unica.com.br> Acesso em 10 de outubro de 2012.

Vieira, V., Machado, R. K., Brey, N. K., \& Rossetto, C. R. (2012). Evidências das pesquisas que abordam a tipologia de Miles e Snow no Brasil. Revista Ibero-Americana de Estratégia, 11(2), 7090. doi: 10.5585/riae.v11i2.1753

Whittington, R. (2006). O que é estratégia. São Paulo: Thomson Learning.

Yin, R. K. (2005). Estudo de Caso: planejamento e métodos. 3a ed. Porto Alegre: Bookman. 